\title{
The Effect of Traffic Facilities Accessibility on Residents' Travel under Block Scale
}

\author{
Yu Ren, Chunrong Zhao, Juanlin Fu \\ School of Civil Engineering and Architecture, Southwest University of Science and Technology, Mianyang, China \\ Email: 1545202906@qq.com
}

How to cite this paper: Ren, Y., Zhao, C. R., \& Fu, J. L. (2020). The Effect of Traffic Facilities Accessibility on Residents' Travel under Block Scale. Open Journal of Social Sciences, 8, 98-110. https://doi.org/10.4236/jss.2020.86010

Received: May 2, 2020

Accepted: June 6, 2020

Published: June 9, 2020

Copyright $\odot 2020$ by author(s) and Scientific Research Publishing Inc. This work is licensed under the Creative Commons Attribution International License (CC BY 4.0).

http://creativecommons.org/licenses/by/4.0/

(c) (i) Open Access

\begin{abstract}
The development of urbanization and motorization has changed the way of life of residents. It greatly increases residents' dependence on motor vehicles, thus causing a series of traffic travel problems. The development of road traffic has become an important research perspective. Especially, the influence of traffic facilities accessibility on residents' travel is of great significance. Based on the questionnaire and SPSS analysis software, this paper discusses the influence of traffic facilities accessibility on the travel mode and distance of residents under the influence of their individual social attributes. The results show that whether the residents own cars, their occupation and their monthly income have influence on the travel distance. Under the influence of control, the number of bus lines, the number of intersections, the distance from the nearest bus station and the distance from the residents travel are negatively correlated, that is, the more bus lines, the more intersections, the farther away from the nearest bus station, the shorter the travel distance of residents. And the way of residents travel is basically determined by the factors of residents' social attributes and residents' travel distance. Traffic construction needs to fully consider the needs of different residents.
\end{abstract}

\section{Keywords}

Block-Scale, Traffic Facilities Accessibility, Travel Mode, Travel Distance

\section{Introduction}

With the rapid development of urban motorization, the number of cars is increasing rapidly. By the end of 2018, the number of cars in China reached 240 million (Figure 1). Traffic congestion caused by cars has become a common concern of all cities in China. Improving residents' travel quality has become one of the important tasks of constructing livable cities. And the impact of road traffic 


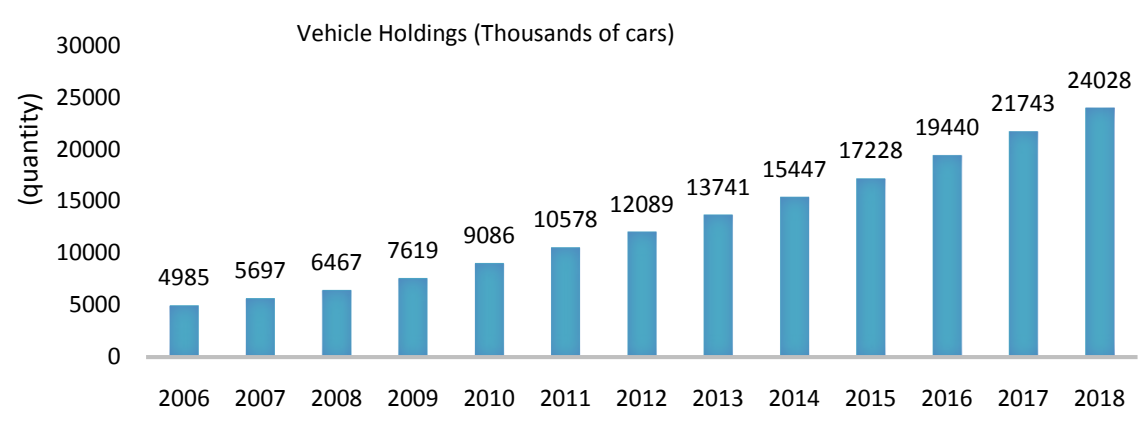

Figure 1. Vehicle holdings in China from 2006 to 2018.

convenience on residents' travel has become a hot topic in traffic research. Therefore, this paper takes gaoshui district of mianyang city as an example to explore the relationship between the two impacts and summarize the analysis results, so as to provide a partial basis for future traffic planning and a research direction for future carbon emission reduction. Over the years, scholars and policy makers from different fields have been seeking effective ways to solve the problem of traffic congestion and improve the quality of residents' travel, Zhan et al. (2018). In 2016, the CPC Central Committee and the State Council issued "some opinions of the CPC Central Committee and the State Council on further strengthening the management of urban planning and construction" pointed out that it is necessary to strengthen the planning and construction of blocks and establish the concept of urban road layout with "narrow roads and dense road networks" (Wang, 2018). Then "narrow road, dense road network and community life circle" is widely used as an important means to manage urban problems.

On the basis of solving urban problems, scholars at home and abroad take the design of road space as one of the focus of attention. There have also been a series of related theoretical works, such as "City Image", "the death and life of big cities in the United States", "Urban Design" and so on. Most studies are based on the establishment of traffic convenience indicators. Some scholars compare and study the subjective traffic convenience evaluation and objective traffic related data to analyze the traffic convenience within the study area (Wang \& Yang, 2012). Some scholars are to directly evaluate the convenience of urban public transport, select the convenience evaluation index such as bus station coverage and average speed of transportation, and construct the evaluation index system of urban public transport convenience (Ren et al. 2015). On this basis, scholars began to explore the impact factors of road traffic. Taking Beijing as an example and combining the objective data of built environment such as block scale with the subjective data of residents' traffic evaluation survey, Zhan et al. (2018) used an orderly multi-classification logic model to explore the influence of block scale characteristics on residents' subjective traffic convenience evaluation and traffic safety evaluation. In terms of bus facilities, Wu (2009) analyzed the correlation between the number of bus stations, bus routes and residents' transportation modes within $300 \mathrm{~m}$ of their homes. It was found that the number of bus routes and bus stations was positively correlated with the probability 
of residents choosing public transport. Foreign scholars Craig et al. (2002) and others have also proved that the proportion of intersection, the form of road layout and the travel environment are also closely related to the choice of residents' travel mode while studying residents' behavior. Frank et al. (2005) studied the relationship between residents' daily travel patterns in Atlanta and the neighborhood environment around their homes, and believed that the more intersections around their homes, the more likely they would choose to walk. Other studies have shown a link between home and the distance to the nearest bus stop and travel. For example, Kitamura et al. (1997) found that the proportion of car trips was positively correlated with the convenience of parking lots and the distance from bus stations.

In recent years, with the community life circle proposed, the micro-scale research more and more focused on human behavior. Scholars at home and abroad have made more achievements in the study of residents' travel. In China, the scholar Ye (2018) set up the travel mode selection model based on the travel chain to realize the scientific analysis and quantitative explanation of the influence of the travel chain factors on the travel choice behavior. Chen et al. (2013) starts from the residents' travel demand and the accessibility demand of various facilities from the low carbon perspective, and builds the urban block with mixed functions, which can help to reduce the traffic congestion on the main road, reduce the proportion of motor vehicle travel within the block, and then reduce the carbon emissions. Based on the basic relationship between built environment and residents' health activities, Li (2017) established a theoretical research framework on the relationship between built environment and residents' health activities behavior. Compared with the domestic research, foreign scholars to the residents travel investigation earlier. Generally speaking, the factors affecting residents' travel can be divided into spatial factors and non-spatial factors. For example Cervero \& Murakam. (2010) and other data based on 370 urbanized areas in the United States, using the structural equation model in space to study the impact of built environment on residents' travel. Cervero \& Kockelmanl (1997) also explored the influence of the three dimensions of built environment (density, diversity, design) on the travel frequency and travel mode selection of residents in San Francisco bay area. On the other hand, scholars Handy et al. (2005) use quasi-longitudinal design to study the relationship between travel preference and travel behavior, while considering the role of travel preference and neighborhood preference in explaining this relationship. Ko et al. (2011) a study of Seoul shows that the top 10\% of high carbon emitters produce about $63 \%$ of traffic carbon emissions and use Tree Logistics models to mine the relationship between residents' socioeconomic attributes and travel carbon emissions. With the rise of the concept of people-oriented, 15-minute life circle, in the field of road traffic analysis, it may be more inclined to analyze the road traffic in the block, especially the impact of personal needs should also be paid attention to. 


\section{Research Areas and Methods}

\subsection{Research Area}

This paper takes the high water area of Mianyang city as an example, divided by many urban roads, and selects 6 residential areas with the urban block as the basic analysis unit (Figure 2). The survey settlements include Jialai Shengshui Home, Garden Xinghe Bay, Cui Man Ting, Changhong Century City, Changxing Pingzheng Anju District and East Wall Street.

\subsection{Data Sources}

The data of this paper are derived from the questionnaire survey of residents' travel situation carried out in Gaoshui District in 2019. The method of household survey and village sampling was used for random survey, and the effective sample size was 747. The samples of each residential area are distributed proportionally according to the number of residential households. The data base includes two parts: sampling survey data and road traffic data. Sample survey data include residents' economic attributes and travel characteristics. Specifically, the economic attributes of residents include age, gender, monthly income, car ownership and occupation. Travel characteristics mainly include residents' travel mode and travel distance. Road traffic convenience mainly involves the improvement of public transport facilities and road connectivity. The former mainly includes the number of bus lines and the distance from the nearest bus station to the home, and the latter refers to the number of intersections on the road (Huang et al. 2015). According to the relevant regulations of the Code of Urban Road Traffic Planning and Design, the distance from the nearest bus station and the number of bus routes in the $300 \mathrm{~m}$ buffer zone are used to calculate the perfect degree of public transport facilities (Figure 3) (Figure 4). The road connectivity is measured to determine the buffer zone with a radius of 800 meters, and the number of road crossings in the buffer zone is counted (Figure 5).

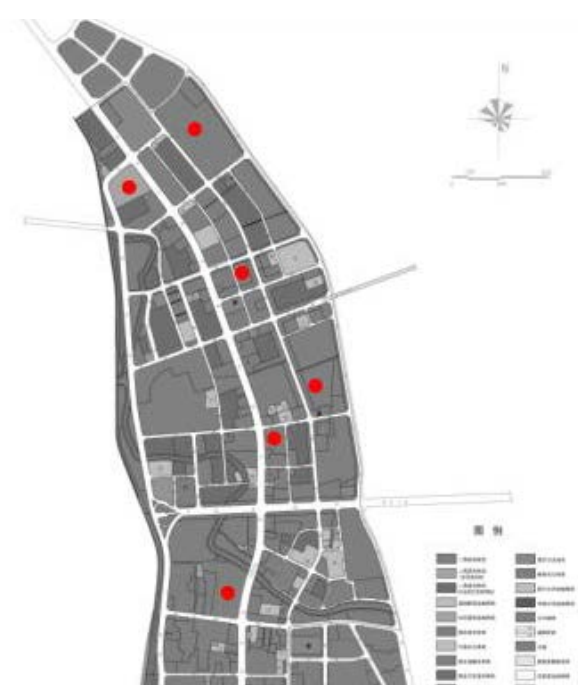

Figure 2. Spatial distribution of samples. 


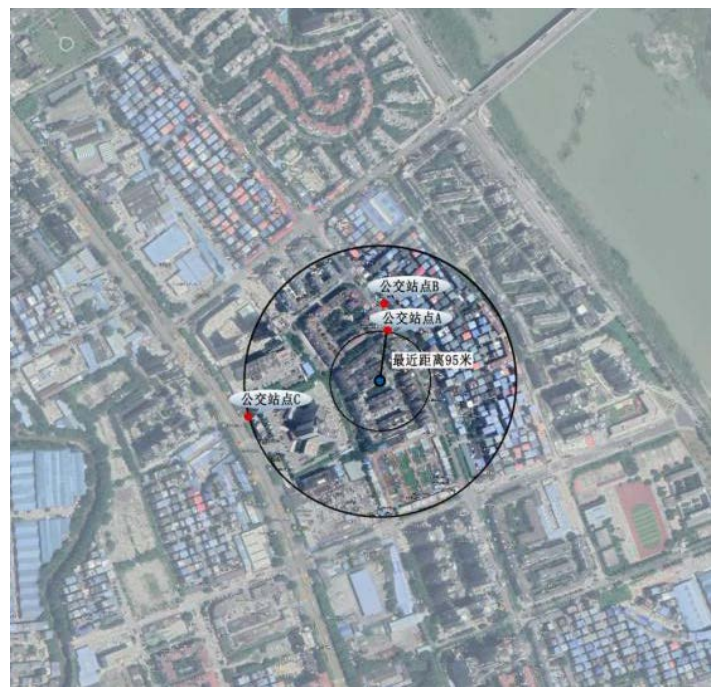

Figure 3. Schematic diagram of distance analysis of nearest bus stop.

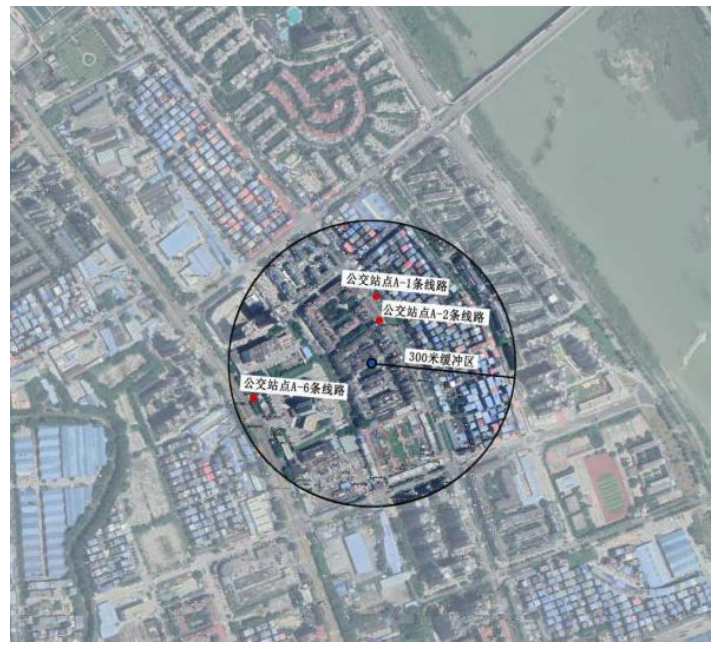

Figure 4. Statistical schematic diagram of the number of bus lines within 300 meters.

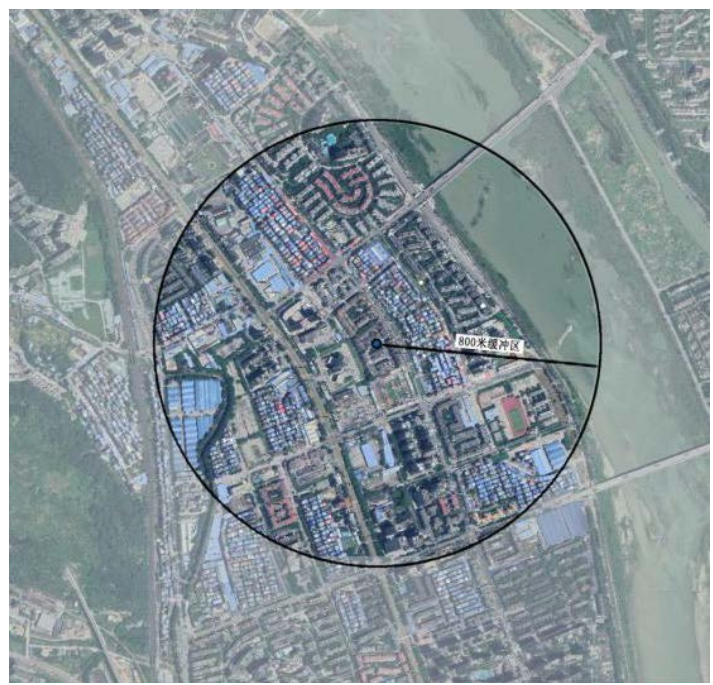

Figure 5. Statistical diagram of the number of road intersections. 


\subsection{Research Methodology}

The main research methods were correlation analysis and multiple logistic regression analysis. Correlation analysis is to judge whether there is a connection between social and economic attributes, residents' travel behavior and road traffic convenience, grasp the direction and degree of correlation, and provide a basis for the use of multiple logistic regression analysis for progress. Multiple logistic regression is also called multiple logistic regression. Based on the analysis of the influence of road traffic convenience on residents' travel distance, the variable of residents' travel distance was taken as the dependent variable and the variable of residents' social attributes as the independent variable. In the study of the impact of road traffic convenience on residents' travel mode, the residents' travel mode is taken as the dependent variable, and the residents' travel distance, road traffic convenience and residents' social attributes are taken as the independent variables.

First of all, the paper makes a statistical analysis of the residents' economic and social attributes, travel behavior and the present situation of road traffic facilities in the questionnaire survey. By analyzing the correlation between residents' social and economic attributes, road traffic convenience and residents' travel behavior through SPSS software, the multivariate regression model of residents' social attribute factors and residents' travel distance was established. By establishing multiple logistic regression model, the paper discusses the influence of road traffic convenience and residents' social attributes on residents' travel mode.

\section{Results and Analysis}

According to the above methods, the data is analyzed, which is mainly about the residents' personal attributes and travel characteristics. The correlation and multiple regression analysis of the relationship between the road traffic convenience, travel distance and travel mode were carried out. By observing the fitting degree of the model and the significance degree of residents' social attributes, the influence relationship was analyzed.

\subsection{Personal Attributes and Travel Characteristics of Residents}

Table 1 shows the personal social attributes and travel patterns of the field research. It can be seen that the proportion of men and women in this study is almost similar, and it also contains residents of all ages. Private cars and walking are the main modes of travel, accounting for $30.1 \%$ and $28.9 \%$ respectively, followed by public transport, accounting for $22.2 \%$, with taxis as the least, accounting for $1.9 \%$.

\subsection{Impact of Road Traffic Convenience on Travel Distance of Residents}

Correlation analysis was used to analyze the relationship between traffic convenience and travel distance of residents in high water area of Mianyang City. 
Table 1. Personal social attributes and travel characteristics of residents.

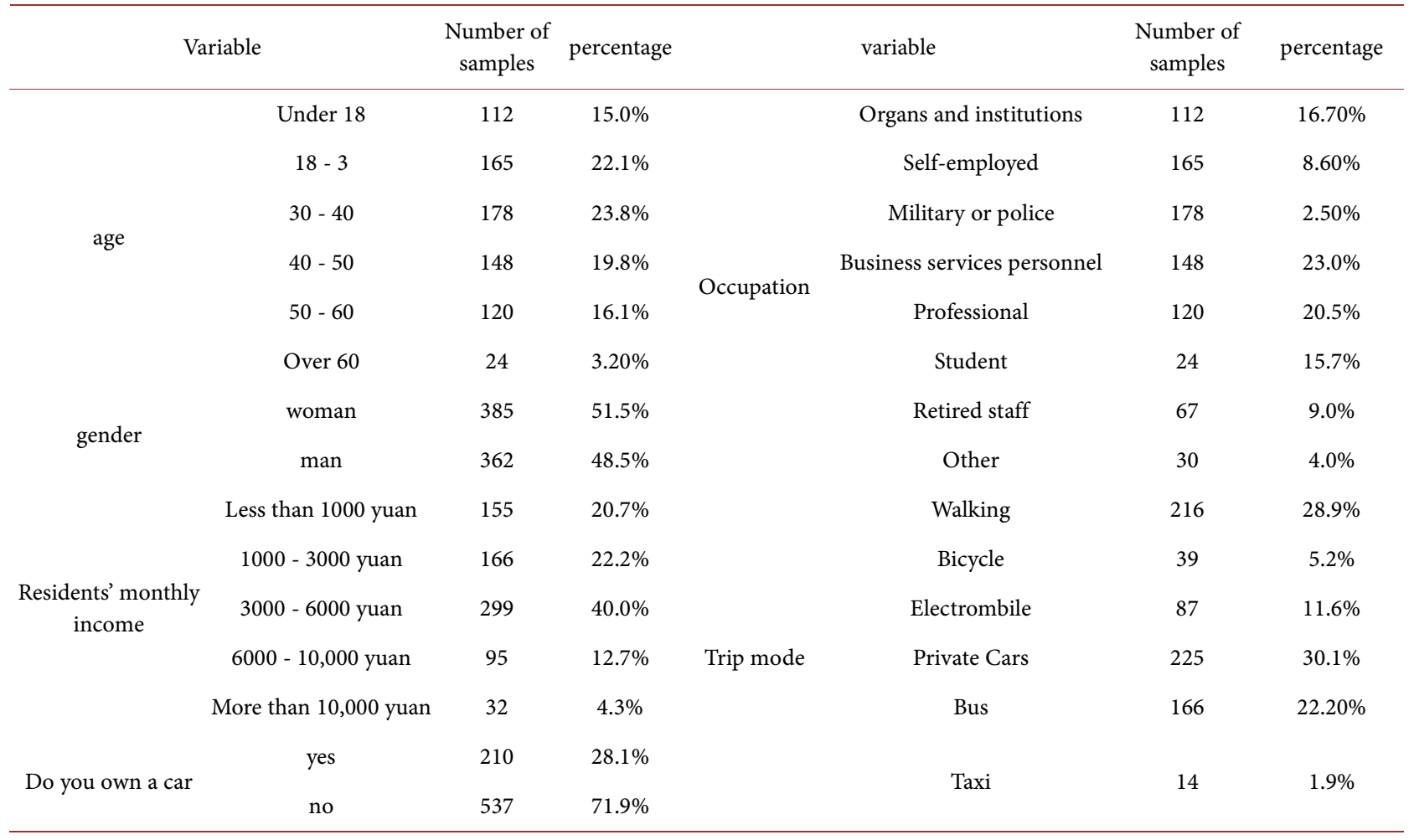

Table 2 shows that the number of bus lines, the number of intersections and the nearest bus stop distance are significantly correlated with the residents' travel distance at 0.05 level, and all of them are negatively correlated. That is, the more bus lines, the more intersections, the farther the nearest bus stop, the shorter the distance residents travel.

On the basis of analyzing the influence of road traffic convenience on residents' travel distance, the multivariate linear regression model between residents' social attributes and residents' travel distance is established. Among them, the resident travel distance variable is the dependent variable, and the resident social attribute variable is the independent variable. By observing the fitting degree of the model and the remarkable degree of the residents' social attribute, the influence of the residents' social attribute factors on the residents' travel distance is analyzed. Table 3 shows that the fitting degree of the model is $42.1 \%$. The sig. values in Table 4 show that the ownership of cars, residents' monthly income and residents' occupational variables are significant, and the established regression model is effective.

The estimated results of the model are shown in Table 5. Whether the residents own cars, the residents' monthly income and the residents' occupation have an impact on the residents' travel distance. And whether the residents own cars and the residents' occupation regression coefficient is -0.693 and -0.087 , respectively, which is negatively correlated with the residents' travel distance. The monthly income coefficient of residents is 0.206 , which is positively correlated 
Table 2. Correlation analysis of road traffic accessibility and residents travel distance.

\begin{tabular}{|c|c|c|c|c|c|}
\hline & & Trip distance & $\begin{array}{l}\text { Number of } \\
\text { bus lines }\end{array}$ & $\begin{array}{c}\text { Number of } \\
\text { intersections }\end{array}$ & Nearest bus stop \\
\hline \multirow{3}{*}{ Trip distance } & Pearson Correlation & 1 & $-0.249^{\star *}$ & $-0.208^{\star *}$ & $-0.160^{\star *}$ \\
\hline & Sig. (2-tailed) & & 0.000 & 0.000 & 0.000 \\
\hline & $\mathrm{N}$ & 747 & 747 & 747 & 747 \\
\hline \multirow{3}{*}{ Number of bus lines } & Pearson Correlation & $-0.249^{\star *}$ & 1 & $0.601^{* *}$ & $0.442^{* *}$ \\
\hline & Sig. (2-tailed) & 0.000 & & 0.000 & 0.000 \\
\hline & $\mathrm{N}$ & 747 & 747 & 747 & 747 \\
\hline \multirow{3}{*}{$\begin{array}{c}\text { Number } \\
\text { of intersections }\end{array}$} & Pearson Correlation & $-0.208^{\star \star}$ & $0.601^{* *}$ & 1 & $0.231^{* *}$ \\
\hline & Sig. (2-tailed) & 0.000 & 0.000 & & 0.000 \\
\hline & $\mathrm{N}$ & 747 & 747 & 747 & 747 \\
\hline \multirow{3}{*}{ Nearest bus stop } & Pearson Correlation & $-0.160^{\star *}$ & $0.442^{\star *}$ & $0.231^{\star *}$ & 1 \\
\hline & Sig. (2-tailed) & 0.000 & 0.000 & 0.000 & \\
\hline & $\mathrm{N}$ & 747 & 747 & 747 & 747 \\
\hline
\end{tabular}

${ }^{* *}$ Correlation is significant at the 0.01 level (2-tailed).

Table 3. Summary of models.

\begin{tabular}{ccccc}
\hline Model & $\mathrm{R}$ & $\mathrm{R}$ Square & Adjusted R Square & Std. Error of the Estimate \\
\hline 1 & $0.357^{\mathrm{a}}$ & 0.127 & 0.126 & 1.28312 \\
2 & $0.408^{\mathrm{b}}$ & 0.167 & 0.164 & 1.25462 \\
3 & $0.421^{\mathrm{c}}$ & 0.177 & 0.174 & 1.24734 \\
\hline
\end{tabular}

aPredictors: (Constant), Do you own a car; ${ }^{b}$ Predictors: (Constant), Do you own a car, monthly income; 'Predictors: (Constant), Do you own a car, monthly income, professional.

Table 4. Analysis of variance.

\begin{tabular}{|c|c|c|c|c|c|c|}
\hline & Model & Sum of Squares & df & Mean Square & $\mathrm{F}$ & Sig. \\
\hline \multirow{3}{*}{1} & Regression & 178.668 & 1 & 178.668 & 108.520 & $0.000^{\mathrm{b}}$ \\
\hline & Residual & 1226.571 & 745 & 1.646 & & \\
\hline & Total & 1405.240 & 746 & & & \\
\hline \multirow{3}{*}{2} & Regression & 234.123 & 2 & 117.061 & 74.368 & $0.000^{c}$ \\
\hline & Residual & 1171.117 & 744 & 1.574 & & \\
\hline & Total & 1405.240 & 746 & & & \\
\hline \multirow{3}{*}{3} & Regression & 249.238 & 3 & 83.079 & 53.398 & $0.000^{\mathrm{d}}$ \\
\hline & Residual & 1156.002 & 743 & 1.556 & & \\
\hline & Total & 1405.240 & 746 & & & \\
\hline
\end{tabular}

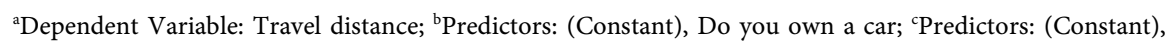

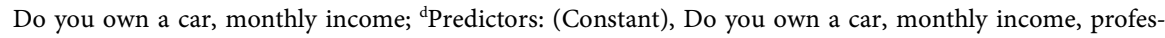
sional.

with the travel distance of residents, indicating that the higher the monthly income, the farther the travel distance. 
Table 5. Coefficient.

\begin{tabular}{|c|c|c|c|c|c|c|}
\hline & \multirow{2}{*}{ Model } & \multicolumn{2}{|c|}{ Unstandardized Coefficients } & \multirow{2}{*}{$\begin{array}{c}\begin{array}{c}\text { Standardized } \\
\text { Coefficients }\end{array} \\
\text { Beta }\end{array}$} & \multirow{2}{*}{$\mathrm{t}$} & \multirow{2}{*}{ Sig. } \\
\hline & & B & Std. Error & & & \\
\hline \multirow{2}{*}{1} & (Constant) & 4.688 & 0.186 & & 25.266 & 0.000 \\
\hline & Do you own a car & -1.088 & 0.104 & -0.357 & -10.417 & 0.000 \\
\hline \multirow{3}{*}{2} & (Constant) & 3.424 & 0.280 & & 12.243 & 0.000 \\
\hline & Do you own a car & -0.774 & 0.115 & -0.254 & -6.726 & 0.000 \\
\hline & Monthly income & 0.280 & 0.047 & 0.224 & 5.935 & 0.000 \\
\hline \multirow{4}{*}{3} & (Constant) & 3.845 & 0.309 & & 12.440 & 0.000 \\
\hline & Do you own a car & -0.693 & 0.117 & -0.227 & -5.905 & 0.000 \\
\hline & Monthly income & 0.206 & 0.053 & 0.165 & 3.921 & 0.000 \\
\hline & Professional & -0.087 & 0.028 & -0.128 & -3.117 & 0.002 \\
\hline
\end{tabular}

${ }^{a}$ Dependent Variable: Travel distance.

On the basis of the regression analysis model, the partial correlation between road traffic convenience and travel distance was analyzed based on the control variables of car ownership, monthly income and occupation. Table 6 shows that under the influence of controlling the social attribute factors of the residents, the number of bus lines, the number of intersections, the distance of the nearest bus stop are significantly correlated with the distance of the residents' travel, and all of them are negatively correlated. That is, the more bus lines, the more intersections, the farther the nearest bus stop distance, the shorter the residents travel distance, and vice versa. The higher the number of intersections indicates that the more convenient the residents are in the blocks, the better the accessibility of the road network, which leads to the reduction of the residents' dependence on private cars and the reduction of the residents' travel distance. There may be two reasons for the number of bus routes and the distance from the nearest bus station. First, the number of bus lines in the land use mix is relatively high, service facilities are relatively complete. The surrounding facilities can meet the basic needs of residents, the farther away from the nearest bus stop from the residential area will reduce the choice of bus travel, so the probability of long distance travel is less. Second, according to the field investigation area found that the convenience of public transport facilities and the abundance of service facilities is one of the conditions for residents to choose housing. According to the questionnaire, most of the activities of local residents are carried out around the residential area, so the influence of personal preference is great.

\subsection{Impact of Road Traffic Convenience on Travel Patterns of Residents}

A number of logistic regression models were established to study the influence of road traffic convenience on residents' travel mode. Taking the mode of residents' 
Table 6. Correlation analysis of road traffic accessibility and travel distance.

\begin{tabular}{|c|c|c|c|c|c|c|c|}
\hline & Control Variables & & Travel distance & $\begin{array}{c}\text { Number of bus } \\
\text { routes }\end{array}$ & $\begin{array}{l}\text { Number of } \\
\text { intersections }\end{array}$ & $\begin{array}{c}\text { The distance to the } \\
\text { nearest bus stop }\end{array}$ & Way to travel \\
\hline & & Correlation & 1.000 & -0.247 & -0.212 & -0.129 & 0.643 \\
\hline & Travel distance & Significance (2-tailed) & . & 0.000 & 0.000 & 0.000 & 0.000 \\
\hline & & df & 0 & 742 & 742 & 742 & 742 \\
\hline & & Correlation & -0.247 & 1.000 & 0.603 & 0.434 & 0.021 \\
\hline & $\begin{array}{l}\text { Number of bus } \\
\text { routes }\end{array}$ & Significance (2-tailed) & 0.000 & . & 0.000 & 0.000 & 0.566 \\
\hline & & $\mathrm{df}$ & 742 & 0 & 742 & 742 & 742 \\
\hline Profecsional \& & & Correlation & -0.212 & 0.603 & 1.000 & 0.229 & -0.003 \\
\hline Monthly income \& & $\begin{array}{l}\text { Number of } \\
\text { intersections }\end{array}$ & Significance (2-tailed) & 0.000 & 0.000 & . & 0.000 & 0.933 \\
\hline Do you own a cal & & $\mathrm{df}$ & 742 & 742 & 0 & 742 & 742 \\
\hline & & Correlation & -0.129 & 0.434 & 0.229 & 1.000 & -0.008 \\
\hline & $\begin{array}{l}\text { The distance to the } \\
\text { nearest bus stop }\end{array}$ & Significance (2-tailed) & 0.000 & 0.000 & 0.000 & . & 0.818 \\
\hline & & $\mathrm{df}$ & 742 & 742 & 742 & 0 & 742 \\
\hline & & Correlation & 0.643 & 0.021 & -0.003 & -0.008 & 1.000 \\
\hline & Way to travel & Significance (2-tailed) & 0.000 & 0.566 & 0.933 & 0.818 & . \\
\hline & & $\mathrm{df}$ & 742 & 742 & 742 & 742 & 0 \\
\hline
\end{tabular}

travel as the dependent variable, the distance of residents' travel, the convenience of road traffic and the social attributes of residents are independent variables. By observing the fitting degree of the model and the remarkable degree of road traffic convenience, the influence of road traffic convenience on residents' travel distance is analyzed. As shown in Table 7, the significant value is less than 0.05 in the model fitting information, and the model has statistical significance. In general, the fit degree of the model is affected by the number of samples (Yao, 2015). The larger the number of samples, the weaker the interpretation degree of the model to the variables and the smaller the fitting degree. But the stability of the model will be better, considering this reason, the sample size is moderate, the $\mathrm{R}$ square value is on the high side, indicating that the model has a high degree of interpretation of the original variables (Table 8).

It can be seen from Table 9 that in the social attributes of residents, the sig. Values of the three variables of age, occupation and car ownership are all less than 0.05 , which have a significant impact on the model. However, the sig. Value of gender and monthly income were 0.279 and 0.165 respectively, which had no significant influence on residents' travel mode. The travel distance of residents also contributes significantly to the model. However, the variable of road traffic convenience has no obvious influence on residents' travel mode.

From the model valuation results of Table 10, it is found that the travel mode of residents is basically determined by the social attribute factors of residents and the distance of residents' travel. In the travel distance of $2 \mathrm{~km}$, the farther 
Table 7. Model fitting information.

\begin{tabular}{ccccc}
\hline \multirow{2}{*}{ Model } & Model Fitting Criteria & \multicolumn{3}{c}{ Likelihood Ratio Tests } \\
\cline { 2 - 5 } & -2 Log Likelihood & Chi-Square & df & Sig. \\
\hline Intercept Only & 2213.601 & & & \\
Final & 1039.593 & 1174.008 & 135 & 0.000 \\
\hline
\end{tabular}

Table 8. R party.

\begin{tabular}{ll}
\hline Cox and Snell & 0.792 \\
Nagelkerke & 0.831 \\
McFadden & 0.512 \\
\hline
\end{tabular}

Table 9. Model likelihood ratio test.

\begin{tabular}{ccccc}
\hline \multirow{2}{*}{ Effect } & Model Fitting Criteria & \multicolumn{2}{c}{ Likelihood Ratio Tests } \\
\cline { 2 - 5 } & $\begin{array}{c}\text { - } \begin{array}{c}\text { - Log Likelihood } \\
\text { of Reduced Model }\end{array} \\
\text { Intercept }\end{array}$ & Chi-Square & df & Sig. \\
Age & $1039.593^{\mathrm{a}}$ & 0.000 & 0 &. \\
Gender & 1087.866 & 48.273 & 25 & 0.003 \\
Professional & 1045.886 & 6.293 & 5 & 0.279 \\
Monthly income & 1094.626 & 55.034 & 35 & 0.017 \\
Do you own a car & 1065.614 & 26.021 & 20 & 0.165 \\
Travel distance & 1283.955 & 244.363 & 5 & 0.000 \\
Number of bus routes & 1472.811 & 433.219 & 20 & 0.000 \\
Number of intersections & $1039.593^{\mathrm{a}}$ & 0.000 & 0 &. \\
The distance to the nearest bus stop & $1039.593^{\mathrm{a}}$ & 0.000 & 0 &. \\
\hline
\end{tabular}

Table 10. Estimated parameters.

\begin{tabular}{|c|c|c|c|c|c|c|c|c|c|}
\hline & \multirow{2}{*}{ Way to travel ${ }^{\mathrm{a}}$} & \multirow{2}{*}{ B } & \multirow{2}{*}{ Std. Error } & \multirow{2}{*}{ Wald } & \multirow{2}{*}{ df } & \multirow{2}{*}{ Sig. } & \multirow{2}{*}{$\operatorname{Exp}(B)$} & \multicolumn{2}{|c|}{ 95\% Confidence Interval for $\operatorname{Exp}(B)$} \\
\hline & & & & & & & & Lower Bound & Upper Bound \\
\hline & Intercept & 59.592 & 4163.533 & 0.000 & 1 & 0.989 & & & \\
\hline \multirow{2}{*}{ Walking } & [travel distance $=$ within $2 \mathrm{~km}$ ] & 4.613 & 1.862 & 6.139 & 1 & 0.013 & 100.786 & 2.622 & 3873.942 \\
\hline & [age $=50-60$ years old $]$ & -2.874 & 0.993 & 8.375 & 1 & 0.004 & 0.056 & 0.008 & 0.396 \\
\hline Bicycle & [age $=50-60$ years old $]$ & -3.639 & 1.123 & 10.491 & 1 & 0.001 & 0.026 & 0.003 & 0.238 \\
\hline Electric cars & [age $=50-60$ years old $]$ & -2.225 & 1.087 & 4.188 & 1 & 0.041 & 0.108 & 0.013 & 0.910 \\
\hline Private car & [owning a car $=$ yes $]$ & 5.021 & 1.197 & 17.595 & 1 & 0.000 & 151.627 & 14.515 & 1583.982 \\
\hline Bus & {$[$ travel distance $=10-20 \mathrm{~km}]$} & -2.374 & 1.178 & 4.060 & 1 & 0.044 & 0.093 & 0.009 & 0.937 \\
\hline
\end{tabular}

the travel distance, the more people choose to walk. In the travel distance of 10 20 kilometers, the farther the travel distance, the fewer people choose to take the 
bus. The more people in the 50 - 60 age group, the fewer people choose bicycles and electric vehicles to travel. The more people own cars, the more people choose cars to travel.

\section{Conclusion}

According to the field investigation data, this paper analyzes the impact of road traffic convenience on residents' travel in high water area of Mianyang city, and provides the basis for optimizing traffic environment and improving travel quality. The study found that road traffic convenience and residents travel distance significantly correlated, but the impact on residents travel mode is relatively small. The main conclusions are:

1) In the high water area of Mianyang, the travel mode of residents is less affected by road traffic convenience, but it is significantly related to the social attributes of residents. Age, occupation, and ownership of a car all affect residents' choice of travel style. Residents pay more and more attention to the quality of life. The way of daily travel is personal preference. And different occupations also determine the economic situation of residents, so that they affect whether to own cars, thus affecting the distance residents travel.

2) The degree of road traffic convenience has a significant negative impact on the travel distance of residents. More road intersections will improve the road network accessibility, increase the setting of public transport stations, greatly reduce the dependence of residents on cars, resulting in a relative reduction in the travel distance of residents. Generally speaking, the land use mix is higher in places with high road traffic convenience, and the farther away from the nearest bus stop in the residential area, the closer the travel distance is when the surrounding facilities basically meet the needs of the residents.

3) In terms of travel distance variables, residents travel distance and travel mode have a significant correlation, and the coefficient is positive. This shows that when the travel distance is large, the probability of residents choosing private car travel mode and bus travel mode is greater than that of walking, bicycle and electric vehicle travel mode.

Of course, the factors that affect residents' travel behavior include not only road traffic convenience factors, but also block scale, road width, building density, volume ratio and other residential development and construction factors. Due to the focus of this paper and the limitation of data, other influencing factors cannot be included in the model together. In addition, in order to improve the traffic environment and the quality of residents' travel, it is necessary to set up the location of public transport stations and the number of lines reasonably, increase the number of road intersections, actively create a small block, dense road network environment, reduce residents' travel distance, reduce residents' travel carbon emissions.

\section{Conflicts of Interest}

The authors declare no conflicts of interest regarding the publication of this paper. 


\section{References}

Cervero, R., \& Kockelman, K. (1997). Travel Demand and the 3Ds: Density, Diversity, and Design. Transportation Research Part D: Transport and Environment, 2, 199-219. https://doi.org/10.1016/S1361-9209(97)00009-6

Cervero, R., \& Murakami, J. (2010). Effects of Built Environments on Vehicle Miles Traveled: Evidence from 370 US Urbanized Areas. Environment and Planning A, 42, 400-418. https://doi.org/10.1068/a4236

Chen, J. F., Lu, Y. P., \& Zhu, X. Y. (2013). Low Carbon City Block Spatial Structure. Planners, 29, 66-70.

Craig, C. L., Brownson, R. C., Cragg, S. E., \& Dunn, A. L. (2002). Exploring the Effect of the Environment on Physical Activity: A Study Examining Walking to Work. American Journal of Preventive Medicine, 23, 36-43. https://doi.org/10.1016/S0749-3797(02)00472-5

Frank, L. D., Schmid, T. L., Sallis, J. F., Chapman, J., \& Saelens, B. E. (2005). Linking Objectively Measured Physical Activity with Objectively Measured Urban Form: Findings from SMARTRAQ. American Journal of Preventive Medicine, 28, 117-125. https://doi.org/10.1016/j.amepre.2004.11.001

Handy, S., Cao, X., \& Mokhtarian, P. (2005). Correlation or Causality between the Built Environment and Travel Behavior? Evidence from Northern California. Transportation Research Part D: Transport and Environment, 10, 427-444.

https://doi.org/10.1016/j.trd.2005.05.002

Huang, J. N., Gao, H. W., \& Han, S. S. (2015). The Effect of Facilities Accessibility on Household Commuting Caused Carbon Emission: A Case Study of Wuhan City, China. Urban Planning International, 30, 97-105.

Kitamura, R., Mokhtarian, P. L., \& Laidet, L. (1997). A Micro-Analysis of Land Use and Travel in Five Neighborhoods in the San Francisco Bay Area. Transportation, 24, 125-158. https://doi.org/10.1023/A:1017959825565

Ko, J., Park, D., Lima, H., \& Hwang, I. C. (2011). Who Produces the Most $\mathrm{CO}_{2}$ Emissions for Trips in the Seoul Metropolis Area? Transportation Research, 16, 358-364. https://doi.org/10.1016/j.trd.2011.02.001

Li, J. (2017). Correlation Study on Built Environment and Physical Activities in Residential Districts. Tianjin: Tianjin University.

Ren, Q. L., Sun, F. R., \& Wang, Y. L. (2015). Study on Evaluation Model of Urban Public Transport Convenience. Journal of Highway and Transportation Research and Development, 32, 127-133.

Wang, D. L., \& Yang, Q. S. (2012). Analysis of Space Characteristics and Problems of Beijing Traffic Convenience. Economic Geography, 32, 49-55.

Wang, J. H. (2018). Study on Planning Mode of Small Scale Urban Blocks in New Town Construction. Suzhou: Suzhou University of Science and Technology.

Wu, J. Y. (2009). Study on the Influence of Block Characteristics on Residents' Transportation. Shanghai: Tongji University.

Yao, Y. (2015). Impacts of Built Environment on Travel Behavior and Carbon Emissions of Urban Residents: A Case Study of Shenzhen. Harbin: Harbin Institute of Technology.

Ye, D. (2018). Research on the Travel Mode Choice Behavior of Residents in Small and Medium-Sized Cities Based on Trip Chain. Chongqing: Chongqing Jiaotong University.

Zhan, L., Zhang, W. W., Chu, Q., Wang, P., \& Li, J. Z. (2018). Impact of Block Size on Residents' Travel Appraisal in Beijing. Progress in Geography, 37, 525-534. 